\title{
A simple complementary approach to reduce risk of contamination with COVID-19 during transesophageal echocardiography
}

\author{
Mohaddeseh Behjati ${ }^{1}$
}

Received: 1 June 2021 / Revised: 2 July 2021 / Accepted: 6 July 2021 / Published online: 12 July 2021

(c) Japanese Society of Echocardiography 2021

Transesophageal echocardiography (TEE) is a semi-invasive Aerosol-Generating Procedure bringing a substantial risk of contamination with novel corona virus (COVID-19) [1]. Thus, current recommendations to diminish the imposed risk during COVID-19 outbreak focusing on "whom, where, and how-to image" by American Society of Echocardiography, providing full PPE for cardiac sonographers by British Society of Echocardiography and so on $[2,3]$. The number of symptomatic cases who need cardiac interventions based on the decisions made using TEE and cannot wait until total pandemic eradication are not limited. Indeed, asymptomatic cases are reluctant to perform swab test. Off course, there is a worldwide shortage of PPE and swab test for COVID-19 is an expensive test, too. Hereby, a simple complementary approach to minimize the exposure of sonographer team to viral load during performing TEE in supine position is proposed. While the team is equipped with standard measures, smaller particles still exist within the environment generated by patients through sneezing, coughing, and/or gagging during or after esophageal intubation. Besides, close contact and face-to-face nature of echocardiography make the importance of these smaller particles even more for echo lab technicians and practitioner. Having sequential cases with these unwanted reactions during COVID-19 pandemic era, we immediately covered their faces by a disposable transparent plastic apron. While patient oxygen saturation is being checked continuously during the whole procedure, a plastic coverage is putted on patient's face (Fig. 1). Patient would receive oxygen in the case of under saturation. This simple method would act as a barrier against spreading patient's droplets and could reduce the sonographer anxiety, too. Indeed, plastic surface would act like oxygen tent and could enhance patient oxygenation, as well. If patient is not receiving oxygen and is unsaturated, construction of this tent could be dangerous by re-inhalation of carbon dioxide. Therefore, in cases with low oxygen saturation, the plastic barrier could be used in accompany with nasal oxygenation. The plastic apron should be transparent making it possible to evaluate the patient breathing status. In my routine practice, if the patient is really COVID-19 symptom free, I go ahead TEE using this method, and after termination of the procedure, we open the windows and leave the room for $20 \mathrm{~min}$. Fortunately, till now, we had no problem regarding being infected by COVID-19 in all of working team using this method. This method could probably diminish the risk of transmission of other air-borne disease.
Mohaddeseh Behjati

behjatimohaddeseh@gmail.com;

dr.mohaddesehbehjati@gmail.com

1 Rajaie Cardiovascular Medical and Research Center, Iran University of Medical Sciences, Valiasr Ave Niayesh Intersection, Tehran, Iran 


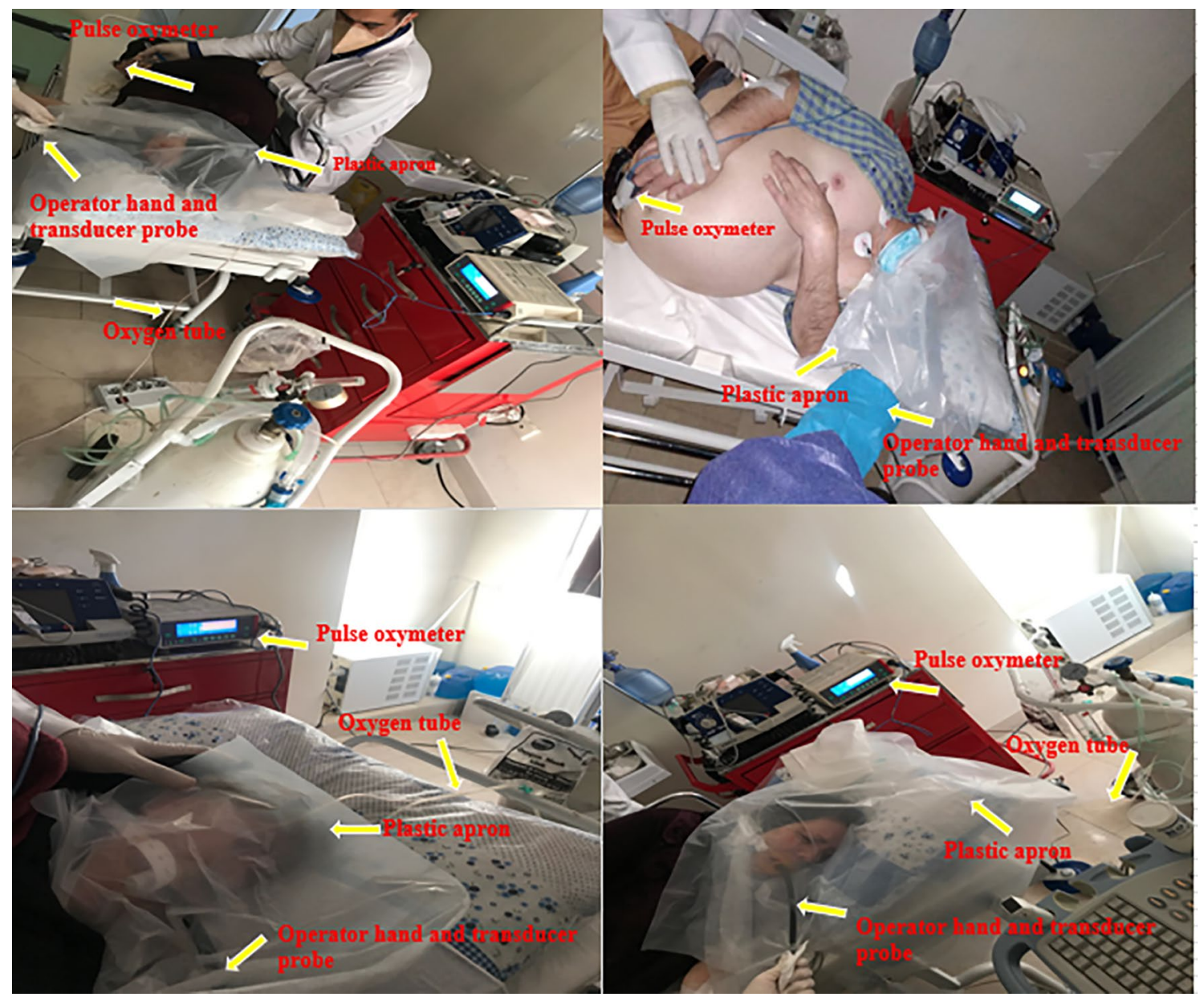

Fig. 1 Application of plastic apron on the patient face during transesophageal echocardiography. Details are shown using arrows

Acknowledgements We thank all the consultants in this work.

Funding There is no grant for this work.

\section{Declarations}

Conflict of interest There is no conflict of interest.

\section{References}

1. Gackowski A, Lipczyńska M, Lipiec P, Szymański P. Expert opinion of the Working Group on Echocardiography of the
Polish Cardiac Society on performing echocardiographic examinations during COVID-19 pandemic. Kardiologia Polska. 2020;78:357-63.

2. Kirkpatrick JN, Mitchell C, Taub C, Kort S, Hung J, Swaminathan M. ASE statement on protection of patients and echocardiography service providers during the 2019 novel coronavirus outbreak: endorsed by the American College of Cardiology. J Am Coll Cardiol. 2020;75(24):3078-84.

3. British Society of Echocardiography. Clinical guidance regarding provision of echocardiography during the COVID-19 pandemic. Full details available at this link. 2020. https://bsecho.org/covid 19. Accessed 7 Apr 2020.

Publisher's Note Springer Nature remains neutral with regard to jurisdictional claims in published maps and institutional affiliations. 